Journal of Education and Educational Development

$8(2), 418-436,2021$

DOI: http://dx.doi.org/10.22555/joeed.v8i2.413

\title{
Evaluating the Psychometric Properties of Workplace Spirituality Scale in Pakistani Context School Teachers
}

\author{
Muhammad Aslam \\ University of the Punjab, Pakistan \\ Abid Hussain Chaudhary \\ University of the Punjab, Pakistan
}

\begin{abstract}
Workplace Spirituality (WS) is recognized as the inner state of individuals and an aspect of their working life. This study was conducted to evaluate the psychometric properties of the Workplace Spirituality Scale (WPS) developed by Petchsawang and Duchon (2009) in Pakistani context school teachers. The present study was quantitative research and used a cross-sectional survey design. The sample for the study consisted of four hundred public school teachers. The data was collected personally by researchers and necessary guidelines were shared with the respondents. EFA and CFA were applied to evaluate the psychometric properties of the Workplace Spirituality Scale (WPS) in the Pakistani context. The results of the statistical analysis confirmed the four factors model (transcendence, mindfulness, compassion, and meaningful work) and ensured the generalizability of WPS. Furthermore, the results of statistical analysis established adequate reliability and validity of WPS. The modifications in this scale are highlighted. The findings of the study indicated that the instrument is valid and reliable which measures workplace spirituality. Further studies may be conducted in a different context to further ensure the dimensionality, reliability, and validity of WPS through different methodologies and techniques.
\end{abstract}

Keywords: psychometric properties, reliability, validity, workplace spirituality scale, workplace spirituality 


\section{Introduction}

The concepts of positive psychology, such as ethics, belief in super force, integrity, mindfulness, trust, kindness, respect, sense of community and peace in the organization, inspiring employees, humanism, compassion, meaningful work, and transcendence are constructing a new concept which is called workplace spirituality. Spirituality in the workplace is recognized as an aspect of the working life of individuals, the inner state of individuals, which is further built and measured by performing meaningful work at the workplace (Ashmos \& Duchon, 2000; Petchsawang \& Duchon, 2009).

This emerging notion of workplace spirituality is taking a very important place in contemporary organizations. The concept of spirituality was prohibited in organizations previously but now it is gradually becoming researchable and acceptable. Thus, the progressive trend of workplace spirituality in management and behavioral sciences is becoming an essential element for the success of organizations. Moreover, it is worth noting that other than management and behavioral sciences disciplines it has also gradually increased regardless of prevailing criticism and hesitations (Azadmarzabadi et al., 2012).

Different studies found that the higher level of workplace spirituality in an organization provides various advantages and benefits including improving trust, creativity, commitment, honesty, ethics, accountability, job satisfaction, motivation, integrity, sharing, involvement, and decreasing absenteeism, conflict, stress and turnover intentions among employees at workplace (Burack, 1999; Delbecq, 1999; Freshman, 1999; Marques et al., 2005; Milliman et al., 2003; Wanger-Marsh \& Conley, 1999). Therefore, the state of workplace spirituality in organizations has been cogitated by researchers, supervisors, and administrators for the satisfaction and motivation of workers and customers (Rastgar et al., 2012). The promotion of workplace spirituality, self-respect, and confidence among employees leads to increase performance, satisfaction, commitment, and efficiency at the workplace (Karkas, 2010).

Currently, the necessity of research on workplace spirituality in organizations is increasing due to its emerging importance in the workplace. Workplace spirituality creates stability and loyalty in workers and increases confidence, interest, and enthusiasm (Beikzadeh et al., 2011). In addition, the role 
of spirituality at the workplace is contributory to the progress of organizations as it provides civilization for society, perfection for organizations, and obligations for the working environment (Mitroff, 2003).

\section{Literature Review}

The word of spirituality has been driven from the Latin word "Spiritus" which is about the metaphysical aspect of things like, breath, soul, and air. Spiritus is discussed as a fundamental aspect of living things that provide energy and spirit to the physical body. This means that spirit is energy, driver, and power that inhabits individuals in life when they are breathing and awake. Workplace spirituality is related to consciousness, meaningful work, teamwork, mindfulness, thinking process, and connection with super force and ultimate reality (Karakas, 2010).

The term workplace spirituality (WS) has different meanings in different academic disciplines. This diversity in meanings creates a challenge to search for a comprehensive definition of workplace spirituality (Tischler et al., 2002). Some scholars of management and behavioral sciences stated that workplace spirituality is the core component of organizational culture (Daniel, 2010; Leigh, 1997). Giacalone and Jurkiewicz (2003) recognized that WS is an element of organizational culture and consisted of such organizational values that create satisfaction, kindness, happiness, and a sense of perfection and connection among workers through the work process at the workplace.

Kolodinsky et al., (2008) stated that workplace spirituality is categorized in three levels namely: individual, organizational and societal level. Individual-level workplace spirituality is related to personal spiritual ideas, feelings, beliefs, and values in a specific workplace. Organizational level workplace spirituality is related to the spiritual ideas, feelings, beliefs, and values of individuals in the organization. Societal level workplace spirituality is related to spiritual thoughts, feelings, beliefs, and values of individuals about relationships with other members of society.

Mitroff and Denton (1999a) indicated that WS is associated with increasing meaningful work among employees, building teamwork, and create a balance between the values of employees and organizational values. Ashmos and Duchon (2000) described WS as the inner aspect of workers and sense of community at the workplace that builds and nurtures by meaningful work. 
Gotsis and Kortezi (2008) described workplace spirituality as nurturing mindfulness, individual perfection, transcendence, and gladness among workers that are recognized in several academic disciplines. Petchsawang and Duchon (2009) describe workplace spirituality as building compassion among workers, practicing mindfulness for increasing meaningful work that facilitates to transcendence aspect of individuals. Saks (2011) stated that WS has been described in different ways by different scholars according to their context and culture. The experts of this notion connected it with various dimensions and concepts such as connectedness with society, organization and oneself, inner life, teamwork, and meaningful work, personal fulfillment, organizational standards, inner self, and connectedness (Ashmos \& Duchon, 2000; Mitroff \& Denton, 1999; Pawar, 2009). Likewise, Giacalone and Jurkiewicz (2004) indicated organizational values, transcendence, and connectedness as the components of WS. Furthermore, Liu and Robertson (2011) anticipated interconnection with super force, with individuals, with all living things, and with nature as the discriminant of WS. However, the review of the literature suggested that the common dimensions of WS are compassion, meaningful work, inner state, mindfulness, teamwork, and transcendence.

Hence, the focuses of this study is on the components of WS projected by Petchsawang and Duchon (2009), namely: transcendence, mindfulness, compassion, and meaningful work. Compassion is a feeling developed for others in terms of care, sympathy, support, and understanding their suffering to provide a solution or relief. It is developing awareness and desire to do good for others (Petchsawang $\&$ Duchon, 2009). Mindfulness is a state of being conscious of happenings around us and being aware at all times. A mindful person is free from distractions and is a person who lives in the present and does not wander about past or future predicaments (Petchsawang \& Duchon, 2009). Mindfulness is friendly attention and mental presence at the workplace. Mindfulness improved attentional stability, attentional control, attentional efficiency, cognitive capacity, cognitive flexibility, positive emotions, hope, confidence, self-regulation of behavior (Good et al., 2015). Meaningful work is a sense of feeling that a person is working on something that is inclined with what he or she wants to achieve in life. Meaningful work gives a person a sense of joy, happiness, and excitement. It is a means of expressing one's inner self at work (Petchsawang \& Duchon, 2009). Meaningful work contributed towards individual and organizational purposefulness, commitment, independence, control, engagement, accomplishment, proficiency, growth, mastery, self-realization, and 
achievement at the workplace (Fairle, 2011).

Transcendence explains a sense of connection with a higher power that gives him or her experiences of joy or bliss at work. Transcendence is a spiritual term and not a religious term that includes connectedness to God (Petchsawang \& Duchon, 2009). Transcendence contributed towards widespread connectedness, enjoyment, limitless purpose, unity among individuals, and emotional closeness of employees at the workplace (Lace et al., 2017).

The measurement of different constructs is the concern of researchers all the time and for measurement of any construct, there is a need for a valid and reliable instrument or scale. Therefore, for measurement of WS of workers Petchsawang and Duchon (2009) constructed and validated WPS in the South Asian context which covering above discussed four dimensions of workplace spirituality. This WPS consisted of twenty-two items, including four components namely: compassion (4 statements) with Alpha value 0.63 and Sample statements are: "I am aware of and sympathize with others" and "I am aware of my co-workers' needs", mindfulness (6 statements) with Alpha value 0.79 and Sample statements are: "I find myself working without paying attention" and "It seems I am working automatically without much awareness of what I'm doing", meaningful work (7 statements) with Alpha value 0.78 and Sample statements are: "I experience joy in my work" and "My spirit is energized by my work", and transcendence ( 5 statements) with Alpha value 0.75 and Sample statements are: "I experience moments at work where everything is blissful" and "At times, I experience happiness at work". This 22 statement WPS model fits perfectly in the South Asian context. Associations between each statement and its dimension ranged from 0.34 to 0.81 , and the r-square from 0.12 to 0.71, which provided proof of satisfactory convergent validity of WPS in the South Asian context.

Shrestha (2016) validate this scale in the Nepali context who found that the internal consistency reliability of the compassion dimension was below .70 and discriminant and convergent validity of transcendence dimension did not meet all the criteria to confirm the validity of this scale.

EFA and CFA are two common techniques used in scale adaptation studies. In scale adaptation studies mostly researchers started with EFA and then applied 
CFA. EFA is applied to explore the factors and structure of the scale and CFA is applied to confirm the factors and structure of scale (Orcan, 2018).

\section{Research Purpose}

The core purpose of this research paper was to evaluate the psychometric properties of the Workplace Spirituality Scale (WPS) developed by Petchsawang and Duchon (2009) in Pakistani context school teachers through EFA and CFA. In addition, this scale would be useful for the measurement of the workplace spirituality of teachers.

\section{Research Objective}

To evaluate the psychometric properties of the Workplace Spirituality Scale in Pakistani context school teachers through EFA and CFA.

\section{Research Questions}

1. How many dimensions of the measurement model of workplace spirituality scale?

2. What are the values of reliability and validity (convergent and discriminant validity) of workplace spirituality scale in the Pakistani context?

\section{Methodology}

The present study was conducted to evaluate the psychometric properties of the Workplace Spirituality Scale (WPS) developed by Petchsawang and Duchon (2009) in Pakistani context school teachers. This study was quantitative research and a cross-sectional survey design was applied. The data were collected from 400 public school teachers of the school education department in Punjab, Pakistan. The data was collected personally by researchers. The workplace Spirituality Scale (WPS) developed by Petchsawang and Duchon (2009) was administered for data gathering. WPS was translated into Urdu to unearth more accurate data regarding WS from the teachers of public schools. Orcan (2018) mentioned step by step process for translating a scale into another language. Accordingly, at the first step, two language experts translated the WPS into Urdu. Secondly, one different language expert finalized the translation. In the third step, the translated scale was translated back into English by two new experts. Lastly, these translations were 
evaluated and finalized by one more new translation expert. The final version of WPS consisted of twenty-two items, including four components namely: compassion (4 statements), mindfulness (6 statements), meaningful work ( 7 statements), and transcendence (5 statements) with a six-point Likert scale from SD (1) to SA (6). The Cronbach's Alpha of this scale was 0.85 . There is further need to ensure the dimensionality, reliability, and validity of this scale for utilization of this scale in Pakistani educational organizations context for measurement of WS. Collected data were analyzed by using SPSS 22.0 AMOS. EFA and CFA were applied to evaluate the psychometric properties of the Workplace Spirituality Scale in Pakistani context school teachers.

\section{Findings}

The data were analyzed by using SPSS 22.0 AMOS. EFA and CFA were applied to evaluate the psychometric properties of the Workplace Spirituality Scale (WPS) developed by Petchsawang and Duchon (2009) in Pakistani context school teachers.

\section{Exploratory Factor Analysis (EFA) on WPS}

EFA was performed to explore the dimensions and their respective statements of WPS.

\section{Table 1}

KMO and Bartlett's Test of WPS

\begin{tabular}{lll}
\hline KMO Measure of Sampling Adequacy. & $\mathbf{. 8 8 3}$ \\
\hline \multirow{3}{*}{ Bartlett's Test of Sphericity } & Approx. Chi-Square & 3608.478 \\
& Df & 231 \\
& Sig. & .000 \\
\hline
\end{tabular}

According to Pallant (2016), the data is considered fit for factor analysis if the value of KMO Measure of Sampling Adequacy is higher than 0.6 and the value of Bartlett's Test of Sphericity is statistically significant (i.e. the significant value should be 0.05 or smaller). The value of KMO for the instrument of workplace spirituality is 0.883 and Bartlett's Test of Sphericity is significant. It shows that the data obtained through the workplace spirituality instrument is suitable to run the factor analysis. 


\section{Table 2}

Items' Correlations of WPS

\begin{tabular}{|c|c|c|}
\hline \multicolumn{3}{|c|}{ Communalities } \\
\hline & Initial & Extraction \\
\hline WS1 & 1.00 & .846 \\
\hline WS2 & 1.00 & .738 \\
\hline WS3 & 1.00 & .840 \\
\hline WS4 & 1.00 & .897 \\
\hline WS5 & 1.00 & .734 \\
\hline WS6 & 1.00 & .810 \\
\hline WS7 & 1.00 & .835 \\
\hline WS8 & 1.00 & .870 \\
\hline WS9 & 1.00 & .831 \\
\hline WS10 & 1.00 & .711 \\
\hline WS11 & 1.00 & .710 \\
\hline WS12 & 1.00 & .726 \\
\hline WS13 & 1.00 & .799 \\
\hline WS14 & 1.00 & .872 \\
\hline WS15 & 1.00 & .866 \\
\hline WS16 & 1.00 & .830 \\
\hline WS17 & 1.00 & .894 \\
\hline WS18 & 1.00 & .735 \\
\hline WS19 & 1.00 & .822 \\
\hline WS20 & 1.00 & .867 \\
\hline WS21 & 1.00 & .793 \\
\hline WS22 & 1.00 & .805 \\
\hline
\end{tabular}

Extraction Method: Principal Component Analysis (PCA).

Notes: WS $=$ Workplace Spirituality

The table of communalities demonstrates the values of correlation. All the items extracted from exploratory factor analysis correlate 0.50 or greater than 0.5 . This shows that all the statements are suitable to proceed with the factor analysis. 


\section{Table 3}

Factors Loadings using Eigen Values Criteria

\begin{tabular}{|c|c|c|c|c|c|c|c|}
\hline \multicolumn{8}{|c|}{ Total Variance Explained } \\
\hline \multirow{2}{*}{ Component } & \multicolumn{3}{|c|}{ Initial Eigenvalues } & \multicolumn{3}{|c|}{ Extraction Sums of Squared Loadings } & \multirow{2}{*}{$\begin{array}{c}\text { Rotation } \\
\text { Sums of } \\
\text { Squared } \\
\text { Loadings } \\
\text { Total }\end{array}$} \\
\hline & Total & $\begin{array}{c}\% \text { of } \\
\text { Variance }\end{array}$ & $\begin{array}{c}\text { Cumulative } \\
\%\end{array}$ & Total & $\begin{array}{c}\% \text { of } \\
\text { Variance }\end{array}$ & $\begin{array}{c}\text { Cumulative } \\
\%\end{array}$ & \\
\hline 1 & 6.066 & 27.573 & 27.573 & 6.066 & 27.573 & 27.573 & 5.036 \\
\hline 2 & 3.870 & 17.591 & 45.164 & 3.870 & 17.591 & 45.164 & 3.831 \\
\hline 3 & 1.376 & 6.255 & 51.419 & 1.376 & 6.255 & 51.419 & 2.828 \\
\hline 4 & 1.228 & 5.584 & 57.002 & 1.228 & 5.584 & 57.002 & 3.540 \\
\hline 5 & .987 & 4.485 & 61.487 & & & & \\
\hline 6 & .889 & 4.043 & 65.530 & & & & \\
\hline 7 & .769 & 3.498 & 69.027 & & & & \\
\hline 8 & .698 & 3.172 & 72.199 & & & & \\
\hline 9 & .668 & 3.038 & 75.237 & & & & \\
\hline 10 & .628 & 2.856 & 78.093 & & & & \\
\hline 11 & .565 & 2.567 & 80.660 & & & & \\
\hline 12 & .538 & 2.444 & 83.104 & & & & \\
\hline 13 & .514 & 2.336 & 85.441 & & & & \\
\hline 14 & .464 & 2.107 & 87.548 & & & & \\
\hline 15 & .415 & 1.886 & 89.433 & & & & \\
\hline 16 & .403 & 1.834 & 91.267 & & & & \\
\hline 17 & .362 & 1.645 & 92.912 & & & & \\
\hline 18 & .349 & 1.588 & 94.500 & & & & \\
\hline 19 & .343 & 1.557 & 96.057 & & & & \\
\hline 20 & .327 & 1.484 & 97.541 & & & & \\
\hline 21 & .291 & 1.323 & 98.864 & & & & \\
\hline 22 & .250 & 1.136 & 100.000 & & & & \\
\hline Extraction $\mathrm{Me}$ & PCA & & & & & & \\
\hline
\end{tabular}

Using the Kaiser's criterion, only those factors are considered suitable which has Eigen values more than one. In table 3, it can be seen that four factors are extracted which have Eigen values of more than 1 . These four factors have 
Eigen values $(6.066,3.870,1.376$, and 1.228$)$ respectively. The variance explained by these four factors is $57.003 \%$ of the total variance.

\section{Figure 1}

Scree Plot of the Factors of Workplace Spirituality Scale

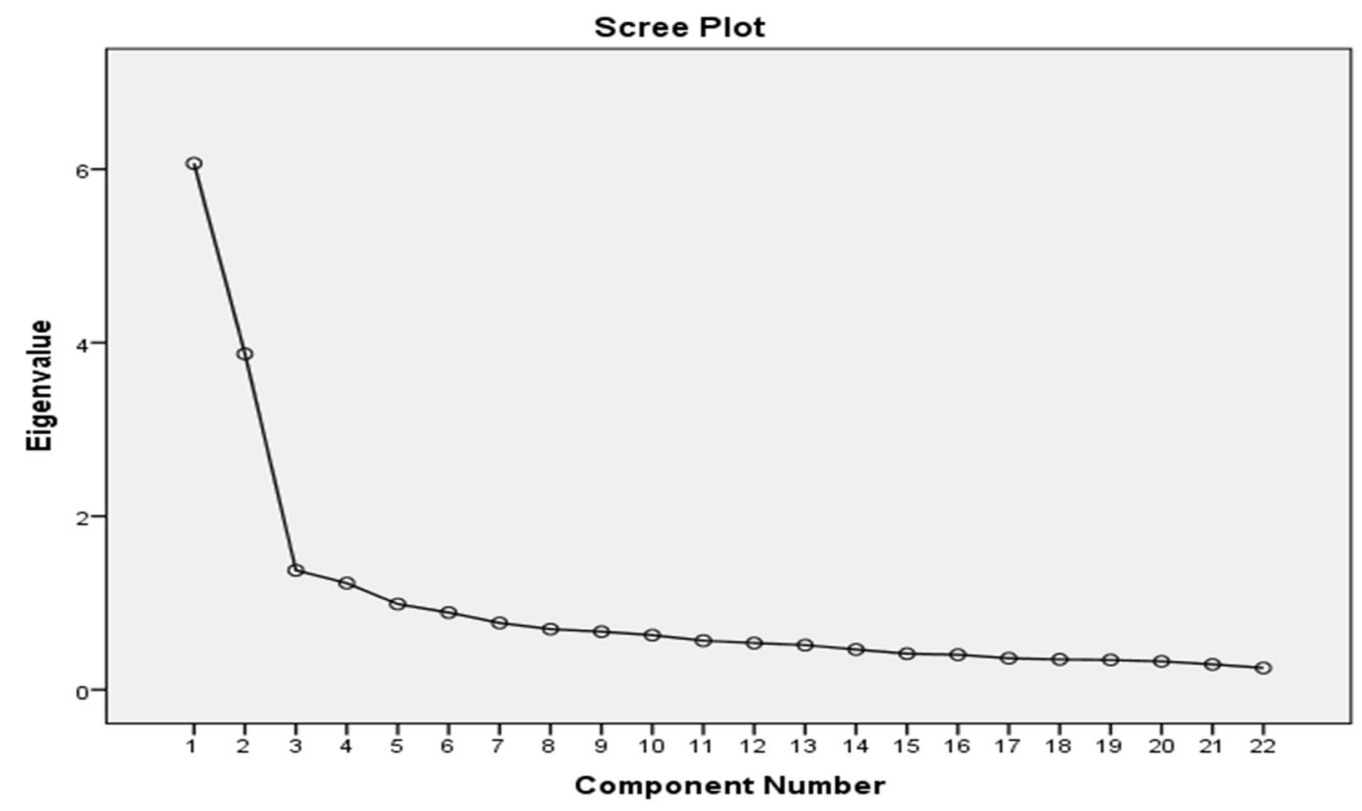

In factor analysis, scree plots are often checked while using Kaiser's criterion. Those components are retained before the alteration (elbow) in the structure of the plot. In the above case, there is a visible breakdown between the $2^{\text {nd }}$ and $3^{\text {rd }}$ components. Component $1^{\text {st }}$ and $2^{\text {nd }}$ apprehend most of the difference than the other components. There is also a small breakdown after the $4^{\text {th }}$ component. Therefore, four components are extracted based on the Scree plot (See figure 1). 
Psychometric Properties of Workplace Spirituality Scale

\section{Table 4}

EFA of Workplace Spirituality Scale using Principal Component

\begin{tabular}{|c|c|c|c|c|}
\hline \multicolumn{5}{|c|}{ Component Matrix } \\
\hline & 1 & 2 & 3 & 4 \\
\hline WS14 & .790 & & & \\
\hline WS3 & .727 & & & .865 \\
\hline WS15 & .701 & & & \\
\hline WS12 & .799 & & & \\
\hline WS16 & .777 & & & \\
\hline WS20 & .755 & & .837 & \\
\hline WS13 & .754 & & & .611 \\
\hline WS2 & .749 & & .813 & \\
\hline WS4 & .729 & & & .841 \\
\hline WS22 & .724 & & .644 & \\
\hline WS11 & .703 & & & .552 \\
\hline WS17 & .794 & & & \\
\hline WS18 & .709 & & .601 & .817 \\
\hline WS8 & & .810 & & \\
\hline WS7 & & .788 & & \\
\hline WS9 & & .781 & & \\
\hline WS10 & & .770 & & \\
\hline WS6 & & .853 & & \\
\hline WS5 & & .890 & & \\
\hline WS1 & & .808 & & \\
\hline WS21 & .332 & .730 & .630 & \\
\hline WS19 & .513 & & & .743 \\
\hline \multicolumn{5}{|c|}{ Extraction Method: PCA } \\
\hline a. four & & & & \\
\hline
\end{tabular}

Using Kaiser's criterion, it can be observed in the above table that four factors are extracted. The items are loaded on four components respectively. Hence, it can be concluded that four factors solution is appropriate. 


\section{Table 5}

EFA of Workplace Spirituality Scale using Pattern Matrix

\begin{tabular}{|c|c|c|c|c|}
\hline & 1 & 2 & 3 & 4 \\
\hline WS13 & .805 & & & \\
\hline WS12 & .768 & & & \\
\hline WS11 & .723 & & & \\
\hline WS15 & .874 & & & \\
\hline WS14 & .871 & & & \\
\hline WS22 & .700 & & & \\
\hline WS16 & .855 & & & \\
\hline WS8 & & .784 & & \\
\hline WS6 & & .782 & & \\
\hline WS7 & & .769 & & \\
\hline WS9 & & .757 & & \\
\hline WS10 & & .751 & & \\
\hline WS5 & & .843 & & \\
\hline WS1 & & .850 & & \\
\hline WS4 & & & .812 & \\
\hline WS3 & & & .750 & \\
\hline WS2 & & & .832 & \\
\hline WS17 & & & .830 & \\
\hline WS19 & & & & .789 \\
\hline WS18 & & & & .725 \\
\hline WS20 & & & & .873 \\
\hline WS21 & & & & .806 \\
\hline
\end{tabular}

Extraction Method: PCA

Rotation Method: Oblimin with Kaiser Normalization.

a. Rotation collected in 30 iterations.

Note: Component 1= Meaningful work, 2= Mindfulness, $3=$ Compassion, 4= Transcendence

Pattern matrix is considered an essential component before making the final judgment about the extraction of the factors. In table 5, it can be seen that the items are loaded on the four components. On the first and second components, 7 items were loaded. Four items were loaded on components 3 and 4. Thus, four components were considered appropriate using the pattern matrix. There was a change in the structure of the model. Initially, statement WS1 was included in 
the factor of compassion, WS17 was included in meaningful work and WS22 was included in transcendence. These statements changed their position and statement WS1 was loaded in mindfulness, WS17 was loaded in compassion and WS22 was loaded in meaningful work after the EFA.

\section{Confirmatory Factor Analysis (CFA) on WPS}

The CFA was used to confirm the best fit model identified in exploratory factor analysis. The preliminary analysis confirmed that the data were normally distributed and data was fit for the application of CFA. The output of CFA $(\chi 2 /$ $\mathrm{CMIN} / \mathrm{DF}=2.983, \mathrm{GFI}=0.95, \mathrm{AGFI}=0.91, \mathrm{TLI}=0.97, \mathrm{CFI}=0.97, \mathrm{RMSEA}$ $=0.041$ ) confirmed the structure of the questionnaire. The confirmatory factor analysis confirmed the four factors for the model.

$\mathrm{Hu}$ and Bentler (1999) gave the threshold to assess the model fit for CFA. According to them, Chi-Square, CMIN/DF value of $\leq 3$ is considered good whereas the value $<5$ is sometimes permissible for model fit. In the present study, the value of CMIN/DF is 2.983 which is below the threshold value given by $\mathrm{Hu}$ and Bentler (1999). Furthermore, the value of CFI $>0.95,>0.90$, and $>0.80$ is considered great, traditional, and sometimes permissible. The value obtained for CFI in this study is 0.97 which is in between the threshold values given by $\mathrm{Hu}$ and Bentler (1999). The value of TLI (Tucker Lewis Index) is considered good if it is higher than 0.95. The value of TLI in the current study is 0.97 which indicates a good fit for the current model. The value of AGFI greater than 0.80 is considered good. The value of AGFI in this study is 0.869 which satisfies this assumption. The value of RMSEA is considered good, moderate, and bad if it is $<0.05,0.05-0.10$, and $>0.10$. In this study, the value of RMSEA is 0.041 which is considered moderate and validates this assumption.

\section{Convergent Validity}

Convergent validity is measured using three different methods. First and foremost, if the loadings of the items are significant and the estimated value is 0.50 or greater, then the construct is achieved convergent validity. In table 2 , all the items in the workplace spirituality instrument loaded above 0.50 , that is, above the cut-off score. It can be concluded that the items of workplace spirituality achieved convergent validity. Secondly, convergent validity is also assessed from the values 
of Average Variance Extracted (AVE). The value of AVE can be evaluated by factor loadings. The formula of AVE is given below.

$$
\mathrm{AVE}={ }^{\mathrm{n}} \Sigma_{\mathrm{i}=0} \mathrm{Li}^{2} / \mathrm{n}
$$

The Li shows the standardized loadings and I represent the number of statements. An AVE of 0.50 or greater is considered adequate for convergent validity. The values of AVE for the constructs of workplace spirituality are given in table 6.

Thirdly, convergent validity is measured in terms of Cronbach's alpha ( $\boldsymbol{\alpha}$ ) and Composite Reliability (CR). The values of $\boldsymbol{\alpha}$ and CR greater than 0.70 are considered adequate to measure the convergent validity of the instrument. The values of $\boldsymbol{\alpha}$ and CR for the constructs of WPS are mentioned in table 6 .

\section{Table 6}

Convergent Validity and Reliability of Factors of Workplace Spirituality Scale

\begin{tabular}{lccc}
\hline Name of factors & Values of AVE & Values of $\boldsymbol{\alpha}$ & Values of CR \\
\hline Compassion & 0.651 & 0.928 & 0.931 \\
Mindfulness & 0.627 & 0.930 & 0.954 \\
Meaningful Work & 0.643 & 0.912 & 0.926 \\
Transcendence & 0.640 & 0.939 & 0.927 \\
\hline
\end{tabular}

Convergent validity is measured in terms of AVE. It is considered good if it is greater than 0.50 . The value of convergent validity of all factors of workplace spirituality is greater than 0.50 which established the assumption of convergent validity. The values of $\boldsymbol{\alpha}$ and $\mathrm{CR}$ for the constructs of workplace spirituality are greater than 0.70 which indicates that convergent validity is established between the items and their respective factors.

\section{Discriminant Validity}

An instrument has adequate discriminant validity if one factor of that instrument is not highly associated with the other factors of that instrument. The value of discriminant validity greater than 0.85 between the two constructs is considered an overlap and statistically, it is said that both the constructs are 
measuring the same thing. The values of discriminant validity for the instrument of workplace spirituality are given in table 7 .

\section{Table 7}

Discriminant Validity of Factors of Workplace Spirituality Scale

\begin{tabular}{lcccc}
\hline Name of factors & $\mathbf{1}$ & $\mathbf{2}$ & $\mathbf{3}$ & $\mathbf{4}$ \\
\hline Compassion & $\mathbf{0 . 8 0 2}$ & & & \\
Meaningful Work & 0.785 & $\mathbf{0 . 8 0 7}$ & & \\
Mindfulness & 0.190 & 0.036 & $\mathbf{0 . 7 9 2}$ & \\
Transcendence & 0.671 & 0.733 & 0.049 & $\mathbf{0 . 8 0 0}$ \\
\hline
\end{tabular}

Discriminant validity is established when the relationship between two factors is less than 0.85 and the square root of AVE must be higher than the value of the relationship between the latent variables. As it is evident from table 8 , the values of each construct for the instrument of workplace spirituality is less than 0.85 and the square root of AVE is higher than the relationship between the latent variables. Hence, it can be concluded that discriminant validity is also established between the constructs.

\section{Discussion}

This study was conducted to evaluate the psychometric properties of the Workplace Spirituality Scale (WPS) developed by Petchsawang and Duchon (2009) in Pakistani context school teachers. The current study found that initially, the statements WS1 were included in the factor of compassion, statement WS17 was included in meaningful work and statement WS22 was included in transcendence. These statements changed their positions and statements WS1 was loaded in mindfulness, WS17 was loaded in compassion and WS22 was loaded in meaningful work after the EFA. In the component matrix table, all items are loaded on four components respectively. The CFA was applied to confirm the best fit model identified in EFA. The preliminary analysis confirmed that the data were normally distributed and data was fit for the application of CFA. The output of CFA confirmed the structure of the scale. The CFA confirmed the four factors for the model. Therefore, it was concluded that four factors solution is appropriate. The findings of this study are similar to the study of Petchsawang and Duchon (2009) that WPS consisted of four factors namely: transcendence, mindfulness, 
compassion, and meaningful work. Further, Shrestha (2016) also confirmed the four factors model of workplace spirituality scale.

All the items in the workplace spirituality scale loaded above 0.50 , are the cut-off score. It was concluded that the items of the workplace spirituality scale achieved convergent validity. Secondly, convergent validity was also assessed from the values of AVE. The values of AVE for the factors of workplace spirituality is greater than 0.50 which also established the assumption of convergent validity. The values of $\boldsymbol{\alpha}$ and CR for the constructs of workplace spirituality were greater than 0.70 which further indicated that convergent validity was established between the items and their respective constructs. The values of each construct for the workplace spirituality scale were less than 0.85 and the square root of AVE was higher than the relationship between the latent variables. Hence, it was concluded that discriminant validity was also established between the constructs. These findings have some inconsistencies with the findings of Shrestha (2016), who found that the internal consistency reliability of compassion dimension was below .70 and discriminant and convergent validity of transcendence dimension did not meet all measures to ensure validity.

\section{Conclusion and Recommendations}

It was concluded that the modifications in the measurement model of WPS were based on the above factor analysis. In the original scale, the statements WS1 were included in the factor of compassion, statement WS17 was included in meaningful work and statement WS22 was included in transcendence. These statements changed their positions statements: WS1 was loaded in mindfulness, WS17 was loaded in compassion and WS22 was loaded in meaningful work after the exploratory factor analysis. The modified version of the workplace spirituality scale consisted of twenty-two items, including four dimensions namely: compassion (4 statements), mindfulness (7 statements), meaningful work (7 statements), and transcendence (4 statements). It was concluded that the results of the statistical analysis confirmed the four factors model (transcendence, mindfulness, compassion, and meaningful work) and ensured the generalizability of WPS. Further, it was concluded that the results of statistical analysis established adequate reliability and validity of WPS.

The present study was conducted to evaluate the psychometric properties 
of the Workplace Spirituality Scale (WPS) developed by Petchsawang and Duchon (2009) in Pakistani context school level teachers. The participants for this study were only teachers taken from school-level educational organizations. Further studies should be conducted to confirm the generalizability of the scale on a large sample from the same organizations and different organizations contexts. Further studies are needed in different contexts to ensure the dimensionality, reliability, and validity through different methodologies and techniques of this scale for the measurement of workplace spirituality.

\section{References}

Ashmos, D. P. \& Duchon. D. (2000). Spirituality at Work: A Conceptualization and Measure. Journal of Management Inquiry, 9(1), 134-145.

Azadmarzabadi, E., Hoshmandja, M., \& Poorkhalil, M. (2012). Relationship between organizational spirituality with psychological empowerment, creativity, spiritual intelligence, job stress, and job satisfaction of university staff. Journal of Behavioral Sciences, 6(2), 181-187.

Burack, E.H. (1999). Spirituality in the workplace. Journal of Organizational Change Management, 12(4), 280-292.

Daniel, J. (2010). The effect of workplace spirituality on team effectiveness. Journal of Management Development, 29(5), 442-456.

Delbecq, L.A. (1999). Christian spirituality and contemporary business leadership. Journal of Organizational Change Management, 12(4), 345-349.

Fairlie, P. (2011). Meaningful work, employee engagement, and other key employee outcomes: Implications for human resource development. Advances in Developing Human Resources, 13(4), 508-525.

Freshman, B. (1999). An exploratory analysis of definitions and applications of spirituality in the workplace. Journal of Organizational Change Management, 12(4), 318 329.

Giacalone, R., \& Jurkiewicz, C. L. (2003). Toward a science of workplace spirituality. In R. A. Giacalone \& C. L. Jurkiewicz (Eds), The handbook of workplace spirituality and organizational performance (pp. 3-28). M.E. Sharpe.

Good, D. J., Lyddy, C. J., Glomb, T. M., Bono, J. E., Brown, K. W., Duffy, M. K., Baer, R. A., Brewer, J. A., \& Lazar, S. W. (2015). Contemplating mindfulness at work: An integrative review. Journal of Management, 42(1), 114-142.

Gotsis, G., \& Kortezi, Z. (2008). Philosophical foundations of workplace spirituality: A critical approach. Journal of Business Ethics, 78(4), 575-600. 
Hu, L. T., \& Bentler, P. M. (1999). Cutoff criteria for fit indexes in covariance structure analysis: Conventional criteria versus new alternatives. Structural equation modeling: A Multidisciplinary Journal, 6(1), 1-55.

Karakas, F. (2010). Spirituality and performance in organizations: A literature review. Journal of Business Ethics, 94(1), 89-106.

Kolodinsky, R., Giacalone, R., \& Jurkiewicz, C. (2008). Workplace values and outcomes: exploring personal, organizational, and interactive workplace spirituality. Journal of Business Ethics, 81(2), 465-480.

Lace, J., Haeberlein, K., \& Handal, P. (2017). Five-factor structure of the spiritual transcendence scale and its relationship with clinical psychological distress in emerging adults. Religions, 8(10), 1-13.

Leigh, P. (1997). The new spirit at work. Training, 51(3), 26-33.

Liu, C., \& Robertson, P. J. (2011). Spirituality in the workplace: Theory and measurement. Journal of Management Inquiry 20(1), 35-50.

Marques, J., Dhiman, S., \& King, R. (2005). Spirituality in the workplace: Developing an integral model and a comprehensive definition. The Journal of American Academy of Business, Cambridge, 1(7), 81-91.

Milliman, J., Czaplewski, A.J., \& Ferguson.J. (2003). Workplace spirituality and employee work attitudes: An exploratory empirical assessment. Journal of Organizational Change Management, 16(4), 426 - 447.

Mitroff, I. I., \& Denton, E. A. (1999b). A study of spirituality in the workplace. Sloan Management Review 40(4), 83-93.

Mitroff, I., \& Denton, E. (1999a). A spiritual audit of corporate america: A hard look at spirituality, religion, and values in the workplace. Jossey-Bass.

Mitroff, I.I., (2003). Do not promote religion under the guise of spirituality. Organization, 10(2), 375-378.

Orcan, F. (2018). Exploratory and confirmatory factor analysis: which one to use first. Journal of Measurement and Evaluation in Education and Psychology, 9(4), 414-421.

Pallant, J. (2016). SPSS Survival manual: A step by step guide to data analysis using SPSS program. McGraw-Hill Education.

Pawar, B. S. (2009). Individual spirituality, workplace spirituality and work attitudes: An empirical test of direct and interaction effects. Leadership and Organization Development Journal, 30(8), 759-777.

Petchsawang, P., \& Duchon, D. (2009). Measuring workplace spirituality in an Asian context. Human Resource Development International, 12(4), 459-468. 
Rastgar, A., Jangholi, M., Heidari, F., \& Heidarina, H. (2012). An investigation on the role of spiritual leadership in organizational identification. Studies on General Management, 16, 39-63.

Saks, A. M. (2011). Workplace spirituality and employee engagement. Journal of Management, Spirituality and Religion, 8(4), 317-340.

Shrestha, A. K. (2016). Further validation of workplace spirituality scale in an Eastern context. Journal of Business and Management Research, 1(1), 1-13.

Tischler, L., Biberman, J., \& McKeage, R. (2002). Linking emotional intelligence, spirituality and workplace performance: Definitions, models and ideas for research. Journal of Managerial Psychology, 17(3), 203-218.

Wagner-Marsh, F., \& Conley, J. (1999). The fourth wave: The spiritually-based firm. Journal of Organizational Change Management, 12(4), 292-301. 